\title{
НЕКОТОРЫЕ АСПЕКТЫ ИЗУЧЕНИЯ НУРИНСКОЙ АРХЕОЛОГИЧЕСКОЙ КУЛЬТУРЫ (по материалам поселения Шагалалы II)
}

\author{
(C) 2018 г. М.К. Хабдулина
}

\begin{abstract}
Статья посвящена актуальным проблемам изучения нуринской (федоровской) археологической культуры эпохи бронзы Казахстана. Приведены некоторые результаты исследования поселения Шагалалы II. Кратко дана история открытия и история изучения памятника. На поселении вскрыто около 2000 кв.м. Выделен «усадебный тип» планировки, при котором в единый комплекс входят жилище и хозяйственная постройка. К числу последних относится гончарная мастерская и двор с колодцами, застроенный крупными хозяйственными ямами для хранения пищевых запасов. Свидетельством обитания на поселении Шагалалы II пришлых с юга земледельческих племен являются архитектура крупных двухярусных жилищ и станковая керамика. Новые радиоуглеродные даты относят нуринскую археологическую культуру к XVIIIXVI вв. до н.э. Этим временем следует датировать культурные контакты населения степной бронзы с южными земледельческими цивилизациями среднеазиатских речных бассейнов.

Ключевые слова: археология, Шагалалы II, эпоха бронзы, федоровская (нуринская) археологическая культура, архитектура жилищ, планировка, станковая керамика
\end{abstract}

\section{Введение}

В настоящее время в изучении эпохи бронзы Казахстана мы наблюдаем два взаимосвязанных процесса: накопление материала, ведущее к открытиям социологического и культурно-генетического характера, и обоснование этих источников в виде формирования новых концепций в вопросах периодизации и хронологии истории андроновской культурно-исторической общности. Меняются представления о структуре андроновского единства, уточняются и наполняются деталями содержание отдельных археологических культур. Активное внедрение метода радиоуглеродного датирования изменило датировку начальных и заключительных этапов андроновского времени. Нижний хронологический срез опускается до XXIII-XXII вв. до н.э. Новые даты по степной бронзе приводят к синхронизации этапов исторического процесса по всему Старому Свету и сдвигают вглубь начало раннего железного века. В дальнейшем возможно смыкание дат начала раннего железного века степной Евразии с датами Передней Азии (XV-XIII вв. до н.э.). В такой атмосфере лавинообразной информации необходимо подведение некоторых промежуточных итогов для осмыс- 
ления масштаба назревших проблемных ситуаций.

Одной из актуальных проблем андроноведения является вопрос о статусе нуринской (федоровской) археологической культуры. Масштабные раскопки поселения Шагалалы II, расположенного на кромке лесостепной и степной полосы Северного Казахстана, предоставляют новые материалы для изучения этой проблемы.

\section{Основная часть}

Поселение Шагалалы II расположено на реке Чаглинка и известно в археологии как «чистое» однослойное поселение федоровской (нуринской) археологической культуры [Малютина, 1994]. Памятник был открыт К.А. Акишевым в период целинных экспедиций 1954-1956 гг. В опубликованном им отчете отмечено, что на территории Кокчетавской области [ныне - Акмолинская область - прим. авт.] зафиксированы семь поселений и 15 могильников бронзового века, свыше 100 курганных могильников кочевых племен [Акишев, 1959, с. 15]. На реке Чаглинка им открыты два поселения эпохи бронзы Чаглинка I, II, отсняты их планы [Акишев, 1959, с. 17, 18]. Оба поселения находятся на правом берегу p. Чаглинка, расстояние между ними 100 км.

Поселение Чаглинка І расположено в 50 км севернее г. Кокшетау. Именно это поселение исследовал в 1965-1968 гг. А.М. Оразбаев [Оразбаев, 1970, с. 129-146]. На нем раскопаны шесть из 16 жилищ земляночного типа, получена керамика позднебронзового (саргаринско-алексеевского) облика, выполнена реконструкция жилищ, раскопаны первые колодцы андроновского времени, сделан ана- лиз палеозоологического материала [Оразбаев, 1970; 1972; Макарова, 1970, с. 269-270].

Поселение Чаглинка II, по описанию К.А. Акишева: «Находится на расстоянии 100 км от первого поселения вверх по течению р. Чаглинки, на том же правом берегу в одном километре на север от с. Кенсутколь (Зерендинский район). Оно расположено в 100 м от берегового обрыва и состоит из 7 впадин - остатков полуземлянок. Каждая впадина занимает площадь от 40 до 160 кв.м. Среди остатков землянок расположены четыре прямоугольные ограды, составленные из врытых на ребро каменных плит. Несомненно, что ограды эти более позднего времени и сооружены после того, как поселение было заброшено. Поселение, судя по собранным мелким фрагментам керамики, принадлежит к алакульскому этапу андроновской культуры, а оградки - к поздней бронзе» [Акишев, 1959, c. 18].

Предметом нашего изучения как раз является поселение Чаглинка II, названное нами Шагалалы II (оно же Павловка). Памятник находится в 33 км юго-западнее Кокшетау. Географические координаты: N 5304'32,8', Е 6900'13,5". Ближайший современный поселок - Кеноткель, находится в 1,85 км южнее. С территории памятника видно село Павловка, расположенное в 3,5 км севернее, на левом берегу р. Чаглинки. По наименованию этого села памятник был назван его первым исследователем Т.С. Малютиной - поселение Павловка. Мы предлагаем именовать его поселение Шагалалы II [Хабдулина и др., 2017].

Памятник относится к категории крупных поселений эпохи брон- 
зы. Строения его расположены на возвышенной площадке надпойменной террасы правого берега р. Чаглинки. Площадка памятника окружена с запада и юга сопками, с севера и востока руслом реки. Размеры этой территории $-240 \times 180$ м. Общая площадь памятника около 40 тыс. кв.м. Река Чаглинка на этом отрезке имеет широкую долину, созданную бесчисленным «меандрированием» русла реки. Видно, что в древности река протекала вдоль подошвы сопок и оставила прогиб, окружающий территорию поселения с запада и юга. Возможно, в эпоху бронзы этот прогиб был использован для отвода воды из основного русла. И в этом случае памятник находился как на острове. О существовании этого водного потока свидетельствует овражное углубление, отходящее от реки на юг с восточной стороны надпойменной площадки. На космоснимке видно, что в углу этого мыса расположены развалы четырех строений, которые при визуальном осмотре не фиксируются [Bonora, Sakenov, 2014, p. 130].

В исследовании памятника выделяются три этапа. Первый - это начало раскопок поселения в 1983 г., вызванное необходимостью изучения поселенческого объекта федоровской культуры, руководитель раскопок Т.С. Малютина; второй был предпринят в 2003 г. из-за размывания прибрежных участков руслом реки Чаглинки, руководитель раскопок Б.М. Хасенова. Третий, современный, этап начался в 2010 г. Поселение Шагалалы II является основным стационарным объектом Есильской археологической экспедиции и учебным полигоном археологической практики для студентов и магистрантов ЕНУ им. Л.Н. Гумилева. Руко- водитель раскопок С.К. Сакенов. В 2013-2014 гг. отдельный раскоп на памятнике был заложен Итальянской археологической экспедицией, руководитель раскопок Ж.Л. Бонора [Bonora, Sakenov, 2014, p. 116-117].

На западной половине надпойменной террасы выделяется жилая площадка $(90 \times 80$ м) с двумя компактно расположенными группами жилищ. Южная группа состоит из четырех крупных овальной формы котлованов, расположенных в один ряд. Жилища ориентированы по линии СВ-Ю3 (рис. 1). Вторая группа крупных котлованов ориентирована по линии С3-ЮВ. Их всего четыре с учетом раскопанных в 1983 г. Эти две группы крупных котлованов разделены пространством в 40-50 м, на котором до раскопок фиксировались небольшие западины округлой формы (рис. 1). Всего по отчету 1983 г. жилая площадка содержит 14 котлованов и 12 бессистемно расположенных каменных оградок от погребальных сооружений конца бронзового века. Котлованы жилищ окружены валом, состоящим из золы. Нами на основании отчетного текста 1983 г. сделан план памятника с нумерацией жилищ (рис. 1). В общую нумерацию не включены два жилища, раскопанные Т.С. Малютиной в 1983 г. Из крупных котлованов частично исследовано жилище № 8 .

Раскоп 2010-2016 гг. заложен в центре жилой площадки вне крупных котлованов. На поселении применяется методика сплошного раскопа с исследованием жилищных западин и межжилищного пространства. Всего вскрыта площадь около 2000 кв.м (рис. 1, 2). За все годы работ на поселении Шагалалы II раскопано 10 жилых и хозяйственных сооружений. 


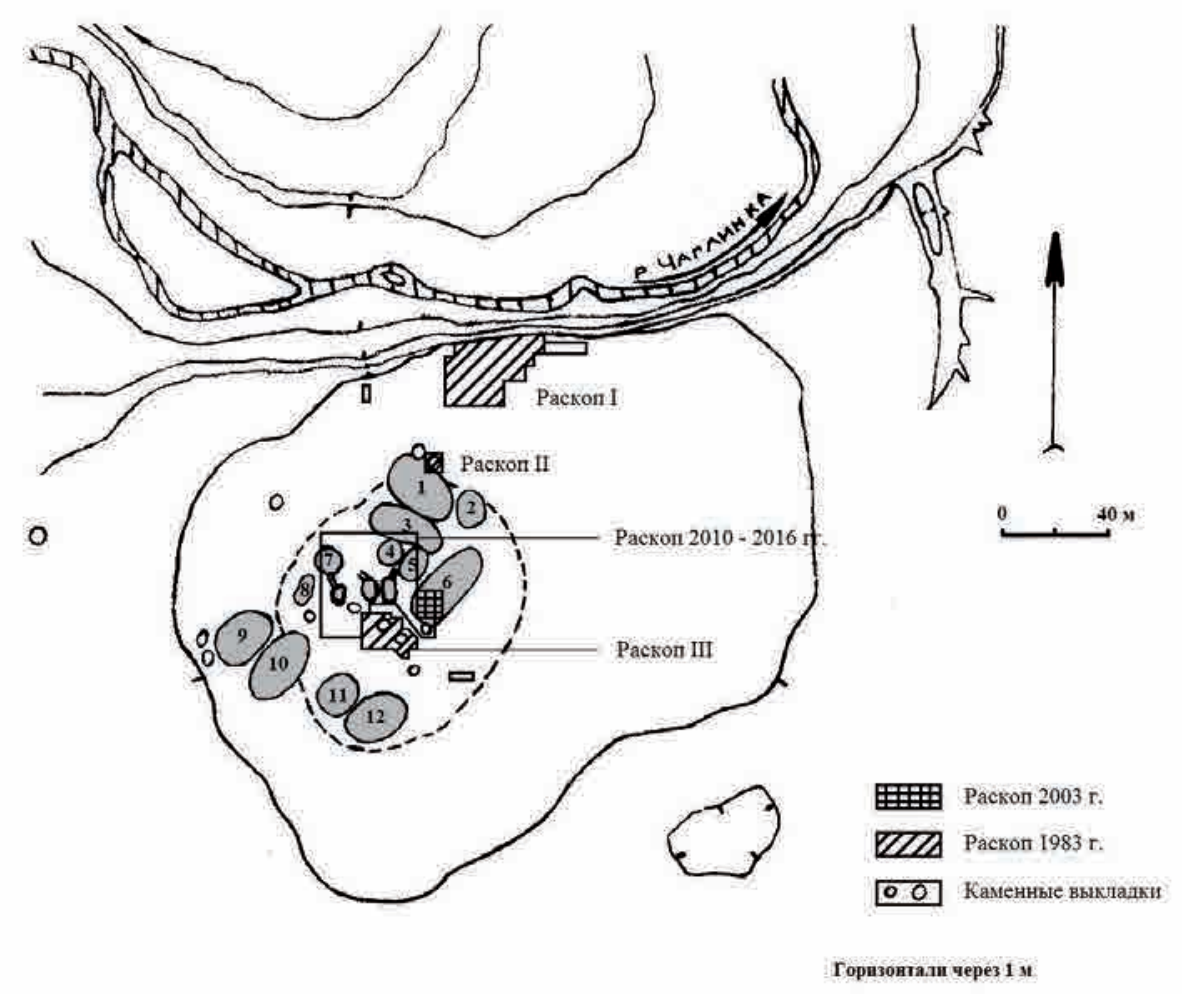

Рис. 1. Поселение Шагалаль ІІ. Топографический план

Fig. 1. The settlement of Shagalaly II. Topographic plan

Общим для них является каркасностолбовая конструкция. Обожженные столбы и плахи фиксируются в придонной части всех строений. Размеры и форма котлованов жилищ свидетельствуют о двух типах жилых конструкций.

На исследованной в 20102016 гг. площадке открыты две линии строений, разделенные «улицей» шириной 10 м (рис. 2). Южный ряд состоит из трех прямоугольной формы жилищ, ориентированных длинной осью по линии С-Ю [Сакенов, 2015, c. 161]. Два жилища (№oo 1, 2) почти смыкаются длинными стенками. Жилище № 3 находится в 10 м западнее. Межжилищное пространство занято хозяйственными ямами, колодцами.
Здесь же раскопаны четыре погребения. Северный ряд строений составляют две наземные конструкции круглой (жил. № 4) и овальной форм (предварительно назван «объект № 1»). По мнению автора раскопок, эти строения возникли во второй период обитания поселка. В их раскопах обнаружена валиковая керамика.

Между этими рядами открыта гончарная мастерская. Все жилища имеют выходы, направленные на север, в сторону реки. Выходы тамбурные, угловые. Судя по расположению столбовых ямок, все входные тамбуры имели двери шириной 1,1 м. Это документируется подпяточными камнями, обнаруженными в проеме входов у столбов. Плоские круглые 


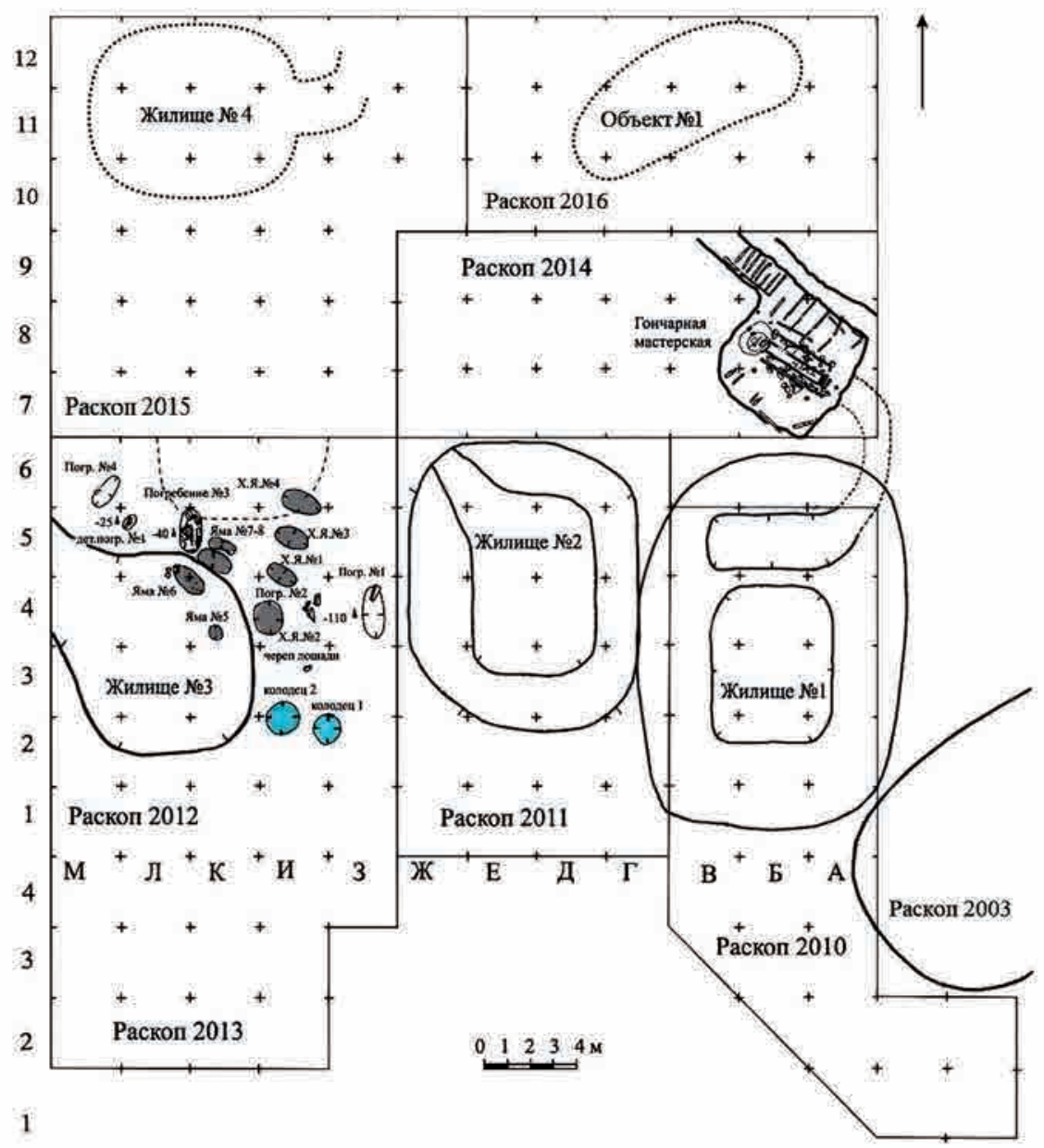

Рис. 2. Поселение Шагалалы II. Сводный план раскопа

Fig. 2. The settlement of Shagalaly II. Excavation master plan

камни в дверной конструкции жилища № 3 и гончарной мастерской были даже стерты на глубину до 1 см. Все жилища по периметру окружены зольником шириной до 2 м и более. Основные находки фрагментов керамики происходят больше из зольников, чем из заполнения жилищ. Зольники содержат обугленное дерево.

Три жилища (№o 1-3) относятся к типу полуземляночных, пол находится на глубине $0,8-1,0$ м от уровня древней поверхности. Вос- точнее жилища № 3 расположена хозяйственная площадка. Она включает два колодца и семь хозяйственных ям. Между ними обнаружены четыре могильные ямы.

В интерьере трех жилищ в центре фиксируется очаг в виде скопления камней или золы. Конструкция дымохода обозначена четырьмя столбовыми ямками, расположенными вокруг очага. С.К. Сакенов на основании полевых наблюдений реконструировал конструкцию жилища № 1, 
имевшего усеченно-пирамидальную четырехскатную кровлю [Сакенов, 2011 , с. 340 , рис. 5]. Такая архитектура характерна и для остальных исследованных им жилищ и имеет аналогии в конструкции федоровских жилищ [Зданович, 1988, с. 22; Малютина, 1990, с. 110-111].

Планировочная структура поселения Шагалалы II позволяет высказать некоторые суждения по организации освоенного пространства. В отличие от традиционной плотной застройки, характерной для поселений эпохи средней бронзы Северного Казахстана, здесь наблюдается разреженная, почти усадебная планировка. Об этом свидетельствуют примыкающие к жилищам хозяйственные постройки. Близкое взаиморасположение позволяет объединить их в отдельные автономные комплексы. Наиболее ярким комплексом является жилище № 1 и расположенная к северу от него гончарная мастерская. Гончарная мастерская трактуется как строение, использовавшееся в летний период. У него отсутствует северо-восточная стенка. Именно к ней ведет выход из жилища № 1. Эти два строения составляют единый комплекс. Возможно, продолжением этого комплекса является конструкция, раскопанная севернее гончарной мастерской в 2016 г. Названа С.К. Сакеновым «объект № 1» (рис. 2).

До раскопок эта конструкция имела вид овальной впадины размерами $16 \times 7$ м, вытянута по линии 3-В. Впадина по периметру окружена зольным валом шириной 1,5-2 м. При зачистке на глубине 40 см выявлено прямоугольное пятно $12 \times 8$ м, ориентированное Ю3-СВ. В заполнении расчищено скопление каменных плит разных размеров, самые крупные - 0,5×075 м. Под северной стенкой выявлены два зольных пятна с прокалом диаметром 1,5 м. За пределами сооружения, в торцовой стороне, фиксировался мощный зольный слой, вперемешку с обугленным деревом, который первоначально, до раскопок, выглядел как вал. В центральной части противоположной стены также найдено множество скоплений из каменных плит разных размеров, а вдоль стены имеются обугленные бревна, расположенные параллельно и перпендикулярно направлениям стен. За пределами этой стены фиксируется незначительный слой золы.

Керамический материал в основном происходит из зольного слоя и трудно с уверенностью соотнести его именно с этим исследуемым объектом. Автор раскопок реконструирует постройку как легкое наземное строение, стены которого были дополнительно укреплены каменными плитами. Внутри нет центрального очага. Возможно, это строение как-то связано с гончарной мастерской. Тем более, что длинный коридорообразный выход мастерской направлен в сторону этой постройки.

Хозяйственная пристройка существовала и у жилища № 2. Это комплекс строений, расположенных между жилищами №№ 2 и 3 . Возможно, эта пристройка была перекрыта общим навесом. Хозяйственный двор включает два колодца глубиной 2 м и семь крупных хозяйственных ям, расположенных в два параллельных ряда. В каждой хозяйственной яме найдена станковая керамика, фрагменты хумов, кости животных. В яме № 6 обнаружена керамическая подставка под хум с нанесенными на его поверхности резными знаками [Ca- 
кенов, 2014, с. 567 , рис. 6]. В яме № 4 найден бронзовый нож и бронзовый наконечник стрелы.

Интерес представляет стратиграфическая позиция жилища № 3 и примыкающей к ней хозяйственной площадки. Судя по плану, на котором яма № 6 находится внутри контуров жилища, а ямы №№ 7 и 8 продолжают общую линию и примыкают к границам котлована № 3, можно утверждать, что жилище № 3 было построено раньше хозяйственной площадки [Сакенов, 2015, с. 161]. Похоже, оно перестало уже функционировать, когда были выкопаны колодцы и хозяйственные ямы. Керамическая гончарная подставка (яма № 6), с нанесенными на ее поверхности знаками, имеет соответствия в слое Намазга VI середины II тыс. до н.э. Это косвенно свидетельствует в пользу более ранней, чем вторая половина II тыс. до н.э., датировки жилища № 3. В целом, можно отметить, что этот комплекс примыкает к жилищу № 2 и является единым с ним.

Таким образом, в планировочной структуре поселения эпохи бронзы Шагалалы II выделяются отдельные комплексы «усадебного типа», включающие жилище и хозяйственные постройки. Исследованные на поселении Шагалалы II жилища относятся к двум типам жилых конструкций. Дома, раскопанные в центре поселения, небольшие по площади - 27-96 кв.м, в то время как дома прибрежной полосы, раскопанные в 1983 г., имеют площадь 162 и 208 кв.м. Они различаются ориентировкой и архитектурой [Хабдулина и др., 2017$].$

Жилища, исследованные в 1983 г., совершенно уникальны и отличны от степных домостроительных традиций бронзового века. Дома примыкают друг к другу длинными сторонами и даже имеют общую стенку. Стены их образованы вертикально вкопанными столбами, основание которых закреплено в глубоких канавках. Судя по чертежам - это был сплошной ряд вертикальных столбов [Хабдулина и др., 2017, с. 54, рис. II, 9]. В центре домов на некотором расстоянии от стен зафиксированы внутренние помещения квадратной формы (9×9 м), стены которых также возведены из вертикальных бревен, вкопанных в канавки. Архитектурно это были капитальные, монументальные строения двухярусной конструкции. Нижний этаж использовался как хозяйственный отсек. Верхний ярус - жилой [Малютина, 1990, с. 113] (рис. 3).

Стены домов были оштукатурены. Об этом свидетельствуют фрагменты глиняных плиток, расчищенные под упавшими бревнами. На этих плитках сохранились с одной стороны отпечатки волокон дерева, с другой - следы пальцев от заглаживания. Дома погибли в огне, фиксируются мощные прокалы, уголь. Как отмечено в тексте отчета: «Прокалы так сильны, что почти вся керамика и сосуды на полу оказались ошлакованными, превратились в керамзит» [Малютина, 1987, с. 19]. Столь сильный огонь связан с конструкцией жилищ, построенных из сосновых бревен, давших сильный жар. Сосновые боры и в настоящее время покрывают сопки и горы Кокшетауской возвышенности.

Комплексный анализ нуринской (федоровской) архитектурной традиции осуществлен Т.С. Малютиной по материалам 30 жилых и производственных построек Южного 


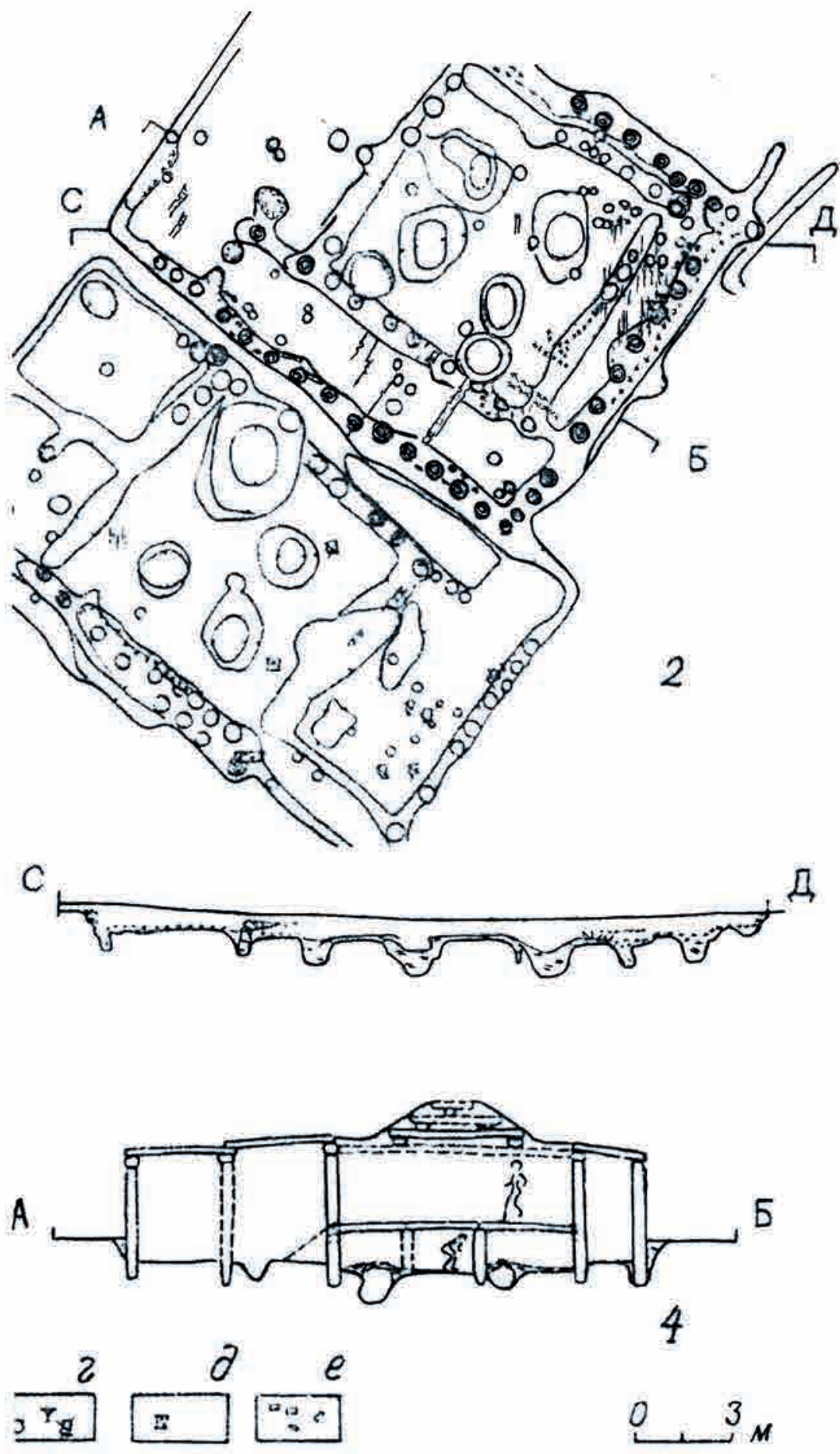

Рис. 3. Архитектура жилищ, исследованных в 19832. (по: [Малютина, 1990, с. 113, рис. 2])

Fig. 3. Architecture of dwellings investigated in 1983 (by: [Malyutina, 1990, p. 113, fig. 2]) 
Зауралья и Казахстана [Малютина, 1990, с. 100-127]. Она характеризует топографию, планировку поселков, выделяет два типа построек, указывает площадь жилищ каждого типа, подробно описывает ведущие признаки архитектуры и конструкции жилищ и производственных строений: входы, стены, кровля, строительный материал, внутренний интерьер. Новые материалы поселения Шагалалы II дополняют и уточняют указанные характеристики и признаки. На примере планировочной структуры поселений Атасу, Кипель сделан вывод, что производственные площадки имеют подчиненное значение и всегда примыкают к жилищам. Данное наблюдение подтверждается и в планировке поселения Шагалалы II. Важной деталью является многообразие хозяйственных ям, их топография, размеры. Содержимое ям свидетельствует об использовании их как кладовых, емкостей для хранения продукции.

Обнаруженные на поселении жертвенные погребения животных, погребения людей, отдельные захоронения черепов, младенцев на межжилищном пространстве, на территории хозяйственных площадок свидетельствуют о сложной системе ритуалов нуринского населения. Такие детали являются всеобщими и выделены Т.С. Малютиной в качестве одного из признаков федоровской (нуринской) культуры [Малютина, 1990, с. 107].

Общим для всех жилищ поселения Шагалалы II является гибель в огне. Независимо от архитектуры и конструкции все они оставлены изза пожара. В культурном слое жилищ зафиксированы обожженные бревна и основания обожженных столбов. Bce жилища окружены мощными зольниками. Это очень интересная и загадочная ситуация, которая может свидетельствовать о преднамеренном пожаре. На полу жилищ остались вещи и сосуды, или развалы сосудов. Найдены целые сосуды, поставленные вверх дном (жил. №№ 1, 8). Факт одновременного огня может свидетельствовать об однослойности памятника.

Результаты исследования поселения Шагалалы II позволяют осветить некоторые теоретические аспекты изучения проблем нуринской культуры: такие как современные представления содержания термина нуринская культура, ее датировка и культурогенез. Проблема изучения культурогенеза, в свою очередь, распадается на выяснение истоков генезиса нуринской археологической культуры, территорию ее сложения, механизм проявления контактов, пути и время миграций.

Термин нуринский появляется в 1966 г. как название этапа региональной периодизации андроновской культуры [Маргулан и др., 1966]. Уже в то время было понятно, что нуринские керамические комплексы Центрального Казахстана имеют локальное своеобразие, отличающее их от федоровской керамики Южного Зауралья и Сибири. Введение термина «нуринский» для андроновских комплексов центра казахских степей предполагало свои закономерности культурного развития. В дальнейшем термин получил распространение в казахстанской археологии. Были предприняты первые обобщения и характеристики нуринской культуры как особой культуры, отличающейся от федоровской и атасуской [Евдокимов, Варфоломеев, 2002, с. 30-39; Ткачев, 2003, с. 26-30; 2011, с. 155]. Классических признаков не так уж много. Они представлены комплексом 
женских украшений, в орнаментации керамики - «косой» заштрихованный треугольник и желобки, отличия от атасуских комплексов наблюдаются в керамической технологии и металлобработке.

\section{Проблема происхождения} нуринской культурь. Масштабные исследования синташтинскопетровских памятников привели к обоснованию концепции происхождения алакульской культуры из синташтинской [Зданович, 2002 , с. 45; Григорьев, 2015, с. 122-123]. Алакульская культура рассматривается как отдельная культурная общность, имеющая сходство со срубной культурой. Поэтому, по мнению ряда ученых, более правомерно на территории Южного Приуралья и Зауралья выделение срубно-алакульской общности. То есть, алакульская культура оказалась узким территориальным образованием. На всей остальной территории, известной как территория андроновской общности, распространены федоровские и синкретичные алакульско-федоровские памятники. Из этого следует, что федоровская культура охватывает весь основной ареал андроновской общности. Осмысление такой ситуации началось в 1970-е годы и привело в конце 1990-х гг. к формированию гипотезы - собственно андроновскими считать только федоровские памятники [Стоколос, 1972, с. 132; Корочкова, 2004, с. 207].

Сложилась проблемная ситуация, связанная с содержанием термина «андроновская культурноисторическая общность». Из ее состава были выведены раннеалакульские культуры (синташта, петровка) и ее верхний хронологический диапазон ограничен началом истории общности культур валиковой кера- мики. Тогда получается, что единственное культурное образование, которое охватывает временные рамки всей андроновской культурноисторической общности, - это нуринская (федоровская) культура. Поэтому часть исследователей считает правомерным именно нуринскую археологическую культуру считать в качестве андроновской. Остальные компоненты андрона относить к отдельным самостоятельным родственным культурам.

Комплекс признаков федоровской культуры сформирован на сопоставлении и сравнении с признаками алакульских памятников конкретной узкой территории Южного Зауралья и позднее был распространен на весь ареал андроновской общности. Поэтому можно утверждать, что известные нам признаки федоровской (нуринской) культуры - это не истинные, реальные ее черты, это - признаки, искаженные пребыванием и ассимиляцией федоровских (нуринских) племен в инокультурной алакульской среде.

В проблеме происхождения нуринской культуры неоднократно отмечалось, что истоки ее следует искать в энеолите и ранней бронзе Восточного и Центрального Казахстана [Кузьмина, 1994, с. 118]. В литературе обсуждаются несколько моделей культурогенеза нуринских племен.

По концепции А.А. Ткачева нуринская культура сложилась в Верхнем Прииртышье на канайской подоснове, возникшей в XVIII-XVII вв. до н.э. «в рамках энеолитической общности культур геометрической керамики» [Ткачев, 2003, с. 33-34; 2011, с. 157-158]. Отсюда начинается радиальная миграция андроновскоканайского населения, которая привела к появлению памятников с фе- 
доровскими чертами на всей территории от Урала до Енисея и далеко на юге, в Средней Азии. В Центральном Казахстане слияние канайских мигрантов с автохтонным населением сформировало нуринскую культуру.

О.Н. Корочковой обоснована модель доандроновского культурогенеза на основе сейминскотурбинского феномена (Рудный Алтай) [Корочкова, 2011]. Возникший на Рудном Алтае самостоятельный очаг сейминско-турбинской металлургии мог стимулировать развитие канайских племен, которые, вне сомнения, оказывались в зоне их культурного воздействия. Это и вызвало активные перемещения андроновскоканайских племен, обладавших более передовыми хозяйственными и культурными достижениями. О федоровской металлообработке, отличающейся от алакульской, пишет С.А. Григорьев. «Федоровские металлурги непосредственно знакомы c сейминско-турбинской металлообработкой» [Григорьев, 2015, с. 344]. Это замечание подкрепляет гипотезу восточно-казахстанского начала культурогенеза нуринских племен.

Предлагается и миграционная модель происхождения федоровской культуры вследствие проникновения древних общин с территории Передней Азии и Южного Закавказья. Маршрут продвижения федоровских племен в Южное Зауралье проходит через Восточный Казахстан и Среднюю Азию [Григорьев, 2000, с. 354].

Это современные теории и модели культурогенеза нуринской общности. Обоснование и дальнейшее развитие любой из предложенных моделей связано с накоплением источников и прежде всего исследованием однослойных поселений. Понашему мнению, таким памятником является поселение Шагалалы II. Главным объектом анализа должны стать стратиграфия жилищ и керамика. Многослойность памятника, несмотря на замечания его исследователей о строительных горизонтах, не вытекает из планиграфии раскопанных жилищ. Присутствие в керамическом комплексе редких экземпляров петровской керамики и валиковой посуды не является чуждым для поселенческой посуды бишкульского типа. Случаи сочетания этих групп керамики в закрытых комплексах неоднократно отмечались исследователями. Гораздо больший интерес вызывает довольно значительный процент среднеазиатской станковой посуды и ее влияние на характеристику нуринской культуры.

В настоящее время мы располагаем статистическим анализом керамического комплекса, выполненного Т.С. Малютиной по раскопкам 1983 г. Коллекция раскопов 1983 г. содержит более 4000 предметов и состоит в основном из керамики [Mалютина, 1987, с. 20]. На дне двух жилищ обнаружены 11 целых сосудов. В керамическом комплексе Т.С. Малютина выделяет две группы керамики: федоровскую (82\%) и гончарную среднеазиатскую (12\%). Среди федоровской группы посуды Т.С. Малютина вычленяет две подгруппы: «павловскую», сочетающую в себе яркие черты классической федоровки и среднеазиатской гончарной керамики. Вторая подгруппа - это бишкульский тип, известный как бытовая поселенческая посуда нуринской культуры [Зданович, 1988, с. 22, 112-113; Малютина, 1991, с. 151-155].

Присутствие в культурном слое поселений станковой среднеазиатской посуды - распространенное явление в памятниках степной 
бронзы. Но чаще гончарная посуда встречается в более поздних комплексах саргаринско-алексеевского времени. В свою очередь, лепная керамика андроновского облика представлена в культурных слоях поселений эпохи бронзы Передней и Средней Азии. Это взаимопроникновение отражает картину исторических контактов степных и южных земледельческих цивилизаций [Кузьмина, 1994, c. 229-231; Массон, 1999, с. 72-77].

Относительно механизма привнесения высказываются мнения о торгово-обменных связях. Несколько иную трактовку позволяют высказать материалы поселения Шагалалы II. Три факта культурного слоя Шагалалы II свидетельствуют о непосредственном и длительном проживании здесь представителей среднеазиатских оазисов. Это архитектура жилищ №№ 1, 2 (1983 г.), гончарная мастерская и выделенный Т.С. Малютиной синкретичный «павловский» тип посуды.

Архитектура жилищ, раскопанных в 1983 г., наиболее ярко сочетает в себе традиции домостроительных стандартов степного населения эпохи бронзы и южных земледельческих регионов. К числу первых следует отнести каркасно-столбовую конструкцию, углубление в грунт (0,3-0,5 м), планировку и направление входов. Инокультурные традиции выражены в оформлении интерьера жилищ: выделении специальных хозяйственных помещений с глубокими хозяйственными ямами с глиняными сводами, глиняная штукатурка стен, переносные керамические очажные подставки [Малютина, 1990, с. 104-106, 110115; Григорьев, 2000, с. 321]. Ярким признаком южного домостроительства является двухярусность жилищ, перекрытие кровли в стиле «чорхо- на». Столь яркое сочетание свидетельствует о длительном проживании групп земледельческого населения на поселении Шагалалы II.

Не менее уникально открытие отдельной постройки со следами специализированной производственной деятельности - гончарной мастерской. В конструкции каменных емкостей и находках отражен промежуточный технологический процесс по изготовлению станковой керамики из местного сырья. Фрагменты и развалы таких грубо изготовленных сосудов обнаружены внутри постройки [Сакенов, 2015, с. 164, 168].

Это открытие логично объясняет присутствие синкретичной посуды, выделенной Т.С. Малютиной как «павловский» тип. Посуда изящная, тонкостенная, вазовидной формы. Ее происхождение является результатом синтеза двух гончарных традиций: степной нуринской и среднеазиатской древнеземледельческой [Малютина, 1991, с. 154-155]. Такое смешение возможно только при длительном совместном проживании не одного поколения гончаров. Результатом длительных культурных контактов является создание новых образцов посуды, своеобразных «сервизов» смешанного облика, изготовленных для знати нуринского общества. К таким относится «павловская» группа керамики. К кругу аналогичных гончарных опытов принадлежит суперстратный компонент бегазы-дандыбаевской керамики, которую В.Г. Ломан предлагает называть «дандыбаевской» по месту первой находки [Ломан, 2013, с. 250253].

Эти факты позволяют утверждать местное (степное) изготовление станковой посуды и крупных хумов. Еще одно свидетельство местного 
изготовления приведено А.С. Ермолаевой при анализе керамического комплекса могильника Измайловка. В ограде 27 найден станковый кувшин, который имеет «местное глиняное сырье, изготовлен на круге, но не обожжен, просто просушен, поэтому был не транспортабелен. Иными словами, привозной была не посуда, а мастера ее готовившие» [Ермолаева, 2012, c. 110].

В истории нуринской культуры выделяют три периода, каждый из которых характеризуется своими особенностями керамического комплекса [Ткачев, 2011, с. 156-157]. Е.Е. Кузьмина относила поселение Павловка (Шагалалы II) к позднефедоровскому времени [Кузьмина, 1994, с. 238]. Дальнейшие анализы и статистические подсчеты позволят уточнить внутреннюю хронологию и длительность существования поселения.

По современным данным, нуринская культура датируется второй четвертью II тыс. до н.э. В настоящее время получены большие серии радиоуглеродных дат для всех этапов бронзового века Южного Зауралья и ряда других территорий [Епимахов,
2014, с. 187; Молодин и др., 2014, с. 142, рис. 2]. По ним и, прежде всего, калиброванным датам Лисаковских могильников, алакульский период датируется XVIII-XVI вв. до н.э. В этот же интервал входят федоровские и синкретические алакульскофедоровские памятники [Епимахов, 2014, с. 190, 203].

\section{Заключение}

Таким образом, поселение Шагалалы II - интересный памятник, имеющий ключевое значение в изучении степной бронзы и решении многих проблем нуринской археологической культуры. Назревшей проблемой является определение статуса нуринской археологической культуры. Из этого вытекает роль нуринских племен в сложении бегазыдандыбаевской археологической культуры. Открытия последних лет крупных погребальных сооружений с керамикой нуринской культуры и c архитектурными формами близкими элитным мавзолеям бегазыдандыбаевского типа - дает основания предполагать генетическую связь нуринской и бегазы-дандыбаевской культур.

\section{ЛИТЕРАТУРА}

1. Акишев К.А. Памятники старины Северного Казахстана // ТИИАЭ АН Каз CCP. 1959. T. 7. C. 3-31.

2. Григорьев C.A. Бронзовый век // Древняя история Южного Зауралья: в 2 т. Т. 1. Каменный век. Эпоха бронзы. Челябинск: изд-во ЮУрГУ, 2000. С. 241-409.

3. Григорьев C.A. К проблеме формирования алакульской культуры Зауралья // Этнические взаимодействия на Южном Урале: матер. VI всерос. научн. конф. Челябинск: ЮУрГУ, 2015. С. 119-124.

4. Евдокимов B.В., Варфоломеев В.В. Эпоха бронзы Центрального и Северного Казахстана. Караганда: изд-во КарГУ им. академика Е.А. Букетова, 2002. 138 с.

5. Епимахов A.B. Динамика коммуникаций бронзового века Урала // Таинство этнической истории древнейших номадов степной Евразии. Сост. В.А. Новоженов, гл. ред. А.В. Епимахов. Алматы: “Остров Крым”, 2014. С. 125-205.

6. Ермолаева А.С. Памятники предгорной зоны Казахского Алтая (эпоха бронзыраннее железо). Алматы: Институт археологии им. А.Х. Маргулана, 2012. 238 с., илл.

7. Зданович Г.Б. Бронзовый век Урало-Казахстанских степей (основы периодизации). Свердловск: изд-во УрГУ, 1988. 184 с.

8. Зданович Г.Б. Урало-Казахстанские степи в эпоху средней бронзы: научн. доклад в виде дис. ... докт. ист. наук. Челябинск: Челяб. ун-т, 2002. 55 с. 
9. Корочкова О.Н. К обсуждению термина «андроновская общность» // Проблемы первобытной археологии Евразии (к 75-летию А.А. Формозова): сб. статей. М.: ИА PAH. 2004. C. 202-211.

10. Корочкова О.Н. Взаимодействие культур в эпоху бронзы в среднем Зауралье и подтаежном Тоболо-Иртышье: факторы, механизмы, динамика: автореф. дис. ... докт. ист. наук. М.: ИА РАН, 2011. 37 с.

11. Кузьмина E.E. Откуда пришли индоарии? Материальная культура племен андроновской общности и происхождение индоиранцев. М.: «Вост. литература», 1994. 464 c.

12. Ломан В.Г. О культурных типах памятников финала эпохи бронзы Казахстана // Бегазы-дандыбаевская культура Степной Евразии: сб. научн. ст., посвящ. 65-летию Ж. Курманкулова. Отв. ред. А.З. Бейсенов. Алматы: НИЦИА «Бегазы-Тасмола», 2013. C. 247-259.

13. Макарова Л.А. Предварительное сообщение о животных эпохи бронзы поселения Чаглинка// По следам древних культур Казахстана. Ред. М.К. Кадырбаев. Алма-Ата: Наука, 1970. С. 201-206.

14. Малютина Т.С. Поселение и могильник Павловка. В: Отчет. Полевые археологические исследования УКАЭ в Казахстане в 1982-1983 гг. Челябинск, 1987. С. 3-26., илл. // Архив НИИ археологии им. К.А. Акишева при ЕНУ им. Л.Н. Гумилева.

15. Малютина T.C. Поселения и жилища федоровской культуры УралоКазахстанских степей // Археология Волго-Уральских степей: межвуз. сб. научн. тр. Ред. Г.Б. Зданович. Челябинск: Челяб. гос. ун-т, 1990. С. 100-127.

16. Малютина Т.C. Стратиграфическая позиция материалов федоровской культуры на многослойных поселениях казахстанских степей // Древности ВосточноЕвропейской лесостепи: межвуз. сб. научн. тр. Самара: Самарский пединститут, 1991. C. $141-162$.

17. Малютина Т.С. Федоровская культура Урало-Казахстанских степей: автореф. дис. ... канд. ист. наук. М.: ИА РАН, 1994. 27 с.

18. Маргулан А.Х., Акишев К.А., Кадырбаев М.К., Оразбаев А.М. Древняя культура Центрального Казахстана. Алма-Ата: «Наука» КазССР, 1966. 435 с.

19. Массон В.М. О продвижении носителей культур степной бронзы и процессах культурогенеза в древней Средней Азии // Комплексные общества Центральной Евразии в III-I тыс. до н.э.: региональные особенности в свете универсальных моделей. Челябинск-Аркаим, 1999. С. 72-77.

20. Молодин В.И., Епимахов А.В., Марченко Ж.Е. Радиоуглеродная хронология культур эпохи бронзы Урала и юга Западной Сибири: принципы и подходы, достижения и проблемы // Вестник НГУ. Сер.: История, филология. 2014. Т. 13, вып. 3: Археология и этнография. С. 136-167.

21. Оразбаев А.М. Поселение Чаглинка (Шагалалы). Некоторые формы и типы жилищ // По следам древних культур Казахстана. Ред. М.К. Кадырбаев. Алма-Ата: Наука, 1970. С. 129-146.

22. Оразбаев А.М. Колодцы на поселении Чаглинка (Шагалалы) // Поиски и раскопки в Казахстане. Ред. К.А. Акишев. Алма-Ата: Наука, 1972. С. 154-162.

23. Сакенов С.К. Археологические работы на поселении Шагалалы II (Павловка) в 2010 году // Маргулановские чтения-2011: матер. междунар. археол. конф. Астана: ЕНУ им. Л.Н. Гумилева. С. 335-337.

24. Сакенов С.К. Станковая керамика из поселения Шагалалы II (К вопросу о культурных связях племен эпохи бронзы Северного Казахстана и Средней Азии) // Диалог культур Евразии в археологии Казахстана: сб. науч. ст., посвящ. 90-летию со дня рождения выдающегося археолога К.А. Акишева. Астана: ЕНУ им. Л.Н. Гумилева, 2014. С. 557-567.

25. Сакенов C.K. Мастерская на поселении Шагалалы II (Павловка) (предварительные итоги исследования) // Этнические взаимодействия на Южном Урале: матер. VI всерос. научн. конф. Челябинск: ЮУрГУ, 2015. С. 160-169.

26. Стоколос В.С. Культура населения бронзового века Южного Зауралья. М.: Наука, 1972. $168 \mathrm{c.}$

27. Ткачев А.А. Бронзовый век Центрального Казахстана: автореф. дис. ... докт. ист. наук. М.: ИА РАН, 2003. 50 с. 
28. Ткачев A.A. К вопросу о соотношении нуринских комплексов Центрального Казахстана // Маргулановские чтения - 2011: матер. междунар. археол. конф. Астана: ЕНУ им. Л.Н. Гумилева, 2011. С. 155-159.

29. Хабдулина М.К., Тлеугабулов Д.Т., Брынза Т.В., Билялова Г.Д., Кучеров П.Ю. Исследование памятников бронзового века в Акмолинском Приишимье (Поселение Шагалалы II). Астана: ЕНУ им. Л.Н. Гумилева, 2017. 192 с.

30. Bonora G.L., Sakenov S.K. A Topographical and Stratigraphical Periplous around the Bronze Age Settlement of Shagalaly II (Pavlovka), Akmolinsk region, Kazakhstan // Маргулановские чтения-2014: матер. междунар. научн.-практ. конф. Алматы-Павлодар, 2014. C. 107-131.

\section{Сведения об авторе:}

Хабдулина Марал Калымжановна - кандидат исторических наук, доцент кафедры археологии и этнологии, директор НИИ им. К.А. Акишева, Евразийский национальный университет им. Л.Н. Гумилева; mk_khabdulina@mail.ru

\section{НҰРА АРХЕОЛОГИЯЛЫҚ МӘДЕНИЕТІНІН ЗЕРТТЕЛУІНІН КЕЙБІР АСПЕКТІЛЕРІ \\ (Шағалалы II қонысының материалдары бойынша)}

\section{М.Қ. Хабдулина}

Мақала Қазақстандағы қола дәуірінің Нұра (Федоров) археологиялық мәдениетінің зерттелуінің өзекті мәселелеріне арналған. Шағалалы II қонысы зерттелуінің кейбір нәтижелері көрсетілген. Ескерткіштің ашылуы және зерттелу тарихы қысқаша берілген. Қоныста шамамен 2000 шаршы м. аумақ ашылған. Тұрғын үй мен шаруашылық құрылыстарының бірыңғай жүйеге біріктірілген жоспарлаудың «усадьбалық типі» анықталды. Соңғысына қыш-құмыра жасау ұстаханасы, құдықтары бар аула, азық-түлік қорларын сақтауға арналған ірі шаруашылық қамбалары жатады. Шағалалы II қонысын оңтүстіктен келген жер өндеуші тайпалар қоныстанғандығын екіқабатты тұрғын үйлер мен станок білдіктер айғақтайды. Соны радиокөміртектік зерттеулер Нұра археологиялық мәдениетін б.д.д. XVIII-XVI ғғ. деп көрсетеді. Қола дәуірінің далалық тұрғындары мен оңтүстіктегі ортаазиялық өзен бассейндерінде қалыптасқан жер өндеушілер өркениеті арасындағы мәдени байланыстарды осы уақытпен мерзімдеу қажет.

Түйін сөздер: археология, Шағалалы II, қола дәуірі, Нұра археологиялық мәдениеті, тұрғын үйлер архитектурасы, жоспарлау, станок білдіктер

\section{SOME ASPECTS OF STUDYING NURA ARCHAEOLOGICAL CULTURE (based on materials from the settlement of Shagalaly II)}

\section{M.K. Khabdulina}

The article contains some results of the study of the settlement of the Nura culture of Shagalaly II. Is given a brief history of the discovery and history of the study of the monument. At the settlement, about 2000 sq.m. A "manor type" of planning has been singled out, in which dwelling and economic buildings are included in a single complex. The latter include a pottery workshop and a courtyard with wells, built up with large pits for storing food supplies. The evidence of the inhabitation of the agricultural tribes in the settlement of Shagalaly II from the south is the architecture large two-tier houses and easel ceramics. New radiocarbon dates include the Nura archaeological culture by the XVIII-XVI centuries BC. This time it is possible to date the cultural contacts of the steppe bronze population with the southern agricultural civilizations of the Central Asian river basins.

Keywords: archaeology, Shagalaly II, the bronze Age, Nura cultura, dwelling, ceramics, pottery workshop

\section{REFERENCES}

1. Akishev, K. A. 1959. In Trudy Instituta istorii, arheologii i ehtnografii AN KazSSR (Works of the Institute of History, Archaeology and Ethnography of the Academy of Sciences of the Kazakh SSR), 7, 3-31 (in Russian). 
2. Grigor'ev, S. A. 2000. In Drevnyaya istoriya Yuzhnogo Zaural'ya (Ancient History of the Southern Trans-Urals), 1. Chelyabinsk: South Ural State University Publ., 241-409 (in Russian).

3. Grigor'ev, S. A. 2015. In Tairov A.A. (ed.) Etnicheskie vzaimodejstviya na Yuzhnom Urale (Ethnic Interactions in the Southern Urals). Chelyabinsk: South Ural State University Publ., 119-124 (in Russian).

4. Evdokimov, V. V., Varfolomeev, V. V. 2002. Epoha bronzy Central'nogo $i$ Severnogo Kazahstana (The Bronze Age of Central and Northern Kazakhstan). Karaganda: Karagandy State University after academician Buketov, E. A. Publ. (in Russian).

5. Epimahov, A. V. 2014. In Epimahov, A. V. (ed.), Novozhenov, V. A. (comp.) Tainstvo ehtnicheskoi istorii drevneishih nomadov stepnoi Evrazii (Sacrament of the ethnic history of the oldest nomads of the steppe Eurasia). Almaty: "Ostrov Krym” Publ., 125-205 (in Russian).

6. Ermolaeva, A. S. 2012. Pamyatniki predgornoj zony Kazahskogo Altaya (ehpoha bronzy-rannee zhelezo) (Monuments of the foothill zone of the Kazakh Altay (the Bronze Age - early iron). Almaty: Margulan A.Kh. Archaeology Institute (in Russian).

7. Zdanovich, G. B. 1988. Bronzovyj vek Uralo-Kazahstanskih stepej (osnovy periodizacii) (Bronze Age of the Ural-Kazakhstan steppes (the foundations of periodization)). Sverdlovsk: Ural State University (in Russian).

8. Zdanovich, G. B. 2002. Uralo-Kazahstanskie stepi v ehpohu srednej bronzy: nauchn. doklad v vide dis. ... dokt. ist. nauk (Ural-Kazakhstan steppes in the Middle Bronze Age: scientific. report in the form of dis. ... Dr. hist. sciences). Chelyabinsk: Chelyabinsk University (in Russian).

9. Korochkova, O. N. 2004. In Gulyayev, V. L. (ed., comp.) Problemy pervobytnoj arheologii Evrazii (k 75-letiyu A.A. Formozova) (Problems of the Primitive Archaeology of Eurasia (on the 75th anniversary of A. Formozov)). Moscow: Institute of Archaeology RAN, 202-211 (in Russian).

10. Korochkova, O. N. 2011. Vzaimodejstvie kul'tur v ehpohu bronzy v srednem Zaural'e i podtaezhnom Tobolo-Irtysh'e: faktory, mekhanizmy, dinamika: avtoref. dis. ... dokt. ist. nauk (The interaction of cultures in the Bronze Age in the middle Trans-Urals and the subtaiga Tobolo-Irtysh: factors, mechanisms, dynamics: thes. dis. ... Dr. hist. sciences). Moscow: Institute of Archaeology RAN (in Russian).

11. Kuz'mina, E. E. 1994. Otkuda prishli indoarii? Material'naya kul'tura plemen andronovskoj obshchnosti i proiskhozhdenie indoirancev (Where did the Indo-Aryans come from? The material culture of the tribes of the Andronovo community and the origin of IndoIranians). Moscow: "Vostochnaya literature" Publ. (in Russian).

12. Loman, V. G. 2013. In Beisenov, A. Z. (ed.) Begazy-dandybaevskaya kul'tura Stepnoj Evrazii (k 65-letiyu J. Kurmankulova) (Begazy-Dandybay culture of the Steppe Eurasia (on the 65th anniversary of J. Kurmankulov)). Almaty: "Begazy-Tasmola" Publ, 247-259 (in Russian).

13. Makarova, L. A. 1970. In Kadyrbayev, M. K. (ed.) Po sledam drevnih kul'tur Kazahstana (In the footsteps of the ancient cultures of Kazakhstan). Alma-Ata: Nauka Publ., 201-206 (in Russian).

14. Malyutina, T. S. In Archive of the Akishev, K. A. Institute of Archaeology near Eurasian National University named Gumilev, L. N. (in Russian).

15. Malyutina, T. S. 1990. In Zdanovich, G. B. (ed.) Arheologiya Volgo-Ural'skih stepej (Archaeology of the Volga-Ural steppes). Chelyabinsk: Chelyabinsk State University, 100-127 (in Russian).

16. Malyutina, T. S. 1991. In Drevnosti Vostochno-Evropejskoj lesostepi (Antiquities of the East European forest-steppe). Samara: Samara Pedagogical Institute Publ., 141-162 (in Russian).

17. Malyutina, T. S. 1994. Fedorovskaya kul'tura Uralo-Kazahstanskih stepej: avtoref. dis. ... kand. ist. nauk (Fedorov culture of the Ural-Kazakhstan steppes: thes. dis. ... Cand. hist. sciences). Moscow: Institute of Archaeology RAN (in Russian).

18. Margulan, A. Kh., Akishev, K. A., Kadyrbayev, M. K., Orazbayev, A. M. 1966. Drevnyaya kul'tura Central'nogo Kazahstana (Ancient culture of Central Kazakhstan). Alma-Ata: Nauka KazSSR Publ. (in Russian).

19. Masson, V. M. 1999. In Kompleksnye obshchestva Central'noi Evrazii v III-I tys. do n.e.: regional'nye osobennosti v svete universal'nyh modelej (Complex Societies of Central Eurasia in the 3rd - 1st millennium BC: regional features in the light of universal models). Chelyabinsk-Arkaim, 72-77 (in Russian). 
20. Molodin, V. I., Epimahov, A. V., Marchenko, Zh. E. 2014. In Vestnik NGU( Bulletin of the Novosibirsk State University), 13, 3: Archaeology and Ethnography, 136-167 (in Russian).

21. Orazbayev, A. M. 1970. In Kadyrbayev, M. K. (ed.) Po sledam drevnih kul'tur Kazahstana (In the footsteps of the ancient cultures of Kazakhstan). Alma-Ata: Nauka Publ., 129-146 (in Russian).

22. Orazbayev, A. M. 1972. In Akishev, K. A. (ed) Poiski i raskopki v Kazahstane (Searches and excavations in Kazakhstan). Alma-Ata: Nauka Publ., 154-162 (in Russian).

23. Sakenov, S. K. 2011. In Margulanovskie chteniya-2011 (Margulan reading2011). Astana: Eurasian National University named Gumilev, L. N. Publ., 335-337. (in Russian).

24. Sakenov, S. K. 2014. In Khabdulina, M. K. (ed.) Dialog kul'tur Evrazii v arheologii Kazahstana (Dialogue of cultures of Eurasia in archaeology of Kazakhstan). Astana: Eurasian National University named Gumilev, L. N. Publ., 557-567. (in Russian).

25. Sakenov, S. K. 2015. In Tairov A.A. (ed.) Etnicheskie vzaimodejstviya na Yuzhnom Urale (Ethnic Interactions in the Southern Urals). Chelyabinsk: South Ural State University Publ., 160-169. (in Russian).

26. Stokolos, V. S. 1972. Kul'tura naseleniya bronzovogo veka Yuzhnogo Zaural'ya (Culture of the population of the Bronze Age of the Southern Zauralye). Moscow: Nauka Publ. (in Russian).

27. Tkachev, A. A. 2003. Bronzovyi vek Central'nogo Kazahstana: avtoref. dis. ... dokt. ist. nauk (Bronze Age of Central Kazakhstan: thes. dis. ... Dr. hist. sciences). Moscow: Institute of Archaeology RAN (in Russian).

28. Tkachev, A. A. 2011. In Margulanovskie chteniya-2011 (Margulan reading2011). Astana: Eurasian National University named Gumilev, L. N. Publ., 155-159 (in Russian).

29. Habdulina, M. K., Tleugabulov, D. T., Brynza, T. V., Bilyalova, G. D., Kucherov, P. Yu. 2017. Issledovanie pamyatnikov bronzovogo veka v Akmolinskom Priishim'e (Poselenie Shagalaly II) (The study of monuments of the Bronze Age in Akmola Priishimye (Settlement Chagalala II)). Astana: Eurasian National University named Gumilev, L. N. Publ. (in Russian).

30. Bonora, G. L., Sakenov, S. K. 2014. In Margulanovskie chteniya-2014 (Margulan reading-2014). Almaty-Pavlodar, 107-131.

\section{About the Author:}

Khabdulina Maral K. Candidate of Historian sciences, Associate Professor of the Department of Archaeology and Ethnology, Director K.A. Akishev Research Institute, Eurasian national university named L.N. Gumilev;mk_khabdulina@mail.ru

\footnotetext{
Мүдделер қақтығысы туралы ақпаратты ашу. Автор мүдделер қақтығысының жоқтығын мәлімдейді. / Раскрытие информации о конфликте интересов. Автор заявляет об отсутствии конфликта интересов. / Disclosure of conflict of interest information. The author claims no conflict of interest. 